\title{
Presidencialismo en tiempos de pandemia:
}

Ecuador

Presidentialism in times of pandemic: Ecuador

Autor: Ángel Eduardo Torres Maldonado

DOl: https://doi.org/10.19053/16923936.v18.n36.2020.12159

Para citar este artículo:

Torres Maldonado, Á. E. (2020). Presidencialismo en tiempos de pandemia: Ecuador. Derecho y Realidad, 18, (36), 89- 109. 


\title{
PRESIDENCIALISMO EN TIEMPOS DE PANDEMIA: ECUADOR
}

\author{
Presidentialism in times of pandemic: Ecuador \\ Presidencialismo em tempos de pandemia: Equador
}

\section{Ángel Eduardo Torres Maldonado ${ }^{\mathbf{a}}$}

angeltm63@hotmail.com

Recepción: 05 de octubre 2020

Aceptación: 09 de noviembre 2020

\section{RESUMEN}

Los Estados Latinoamericanos, herederos tradicionales del sistema de gobierno presidencial, con ciertas combinaciones de figuras propias de sistemas parlamentarios, incorporan enunciados normativos de división de poderes, aparente en algunos casos. Las reformas constitucionales de los últimos años refuerzan las capacidades de acción y decisión del ejecutivo, como medida encaminada a superar las crisis democráticas e inestabilidad de los regímenes políticos. Las constituciones ecuatorianas de 1998 y 2008 incorporan un vasto reconocimiento de derechos y sus garantías, además, atribuyen amplias competencias a la Función Ejecutiva, en detrimento de la Función Legislativa. El sutil diseño institucional previsto en la Constitución ecuatoriana de 2008 se orienta a consolidar un sistema hiperpresidencial, concentrador del poder político. Este artículo pretende: (i) reflexionar sobre el sistema de gobierno presidencial en tiempos de pandemia; (ii) evidenciar que la Constitución ecuatoriana del 2008, desborda las características esenciales del sistema de gobierno presidencial; y (iii) proponer

* Artículo de reflexión.

a. Máster en Derecho Constitucional, Universidad Andina Simón Bolívar (Quito-Ecuador). Máster en Economía, Universidad de las Américas (Quito-Ecuador). Profesor de Introducción al derecho, Teoría del Estado y la Constitución, Clínica constitucional y Fundamentos del derecho en la Universidad de las Américas (Quito, Ecuador) y juez principal del Tribunal Contencioso Electoral del Ecuador.

Contacto: angel.torres@udla.edu.ec, ORCID ID: 0000-0002-8905-8887. 
medidas para prevenir la preocupante crisis moral aflorada en tiempos de pandemia.

\section{PALABRAS CLAVES}

Concentración de poder; pandemia; corrupción.

\section{ABSTRACT}

The Latin American states, traditional heirs to the presidential system of government, with certain combinations of figures typical of parliamentary systems, incorporate normative statements of division of powers. The constitutional reforms of recent years strengthen the executive's capacities for action and decision-making as a measure to overcome the democratic crises and the instability of political regimes. The Ecuadorian constitutions of 1998 and 2008 incorporate a vast recognition of rights and their guarantees, in addition, they attribute broad competencies to the Executive Function, to the detriment of the Legislative Function. The subtle institutional design provided for in the Ecuadorian Constitution of 2008 is aimed at consolidating a hyperpresidential system that concentrates political power. This article aims to: (i) reflect on the presidential system of government in times of pandemic; (ii) show that the Ecuadorian Constitution of 2008 goes beyond the essential characteristics of the presidential system of government; and (iii) propose measures to prevent the worrying moral crisis that has arisen in times of pandemic.

\section{KEYWORDS}

Concentration of power, pandemic, corruption.

\section{RESUMO}

Os Estados latino-americanos, herdeiros tradicionais do sistema presidencialista de governo, com certas combinações de figuras típicas dos sistemas parlamentaristas, incorporam declarações normativas de divisão de poderes. As reformas constitucionais dos últimos anos reforçam a capacidade de ação e decisão do Executivo, como medida que visa superar a crise democrática e a instabilidade dos regimes políticos. As constituições equatorianas de 1998 e 2008 incorporam um amplo reconhecimento dos direitos e de suas garantias, além disso, atribuem amplos poderes ao Poder Executivo, em detrimento do Legislativo. 0 sutil desenho institucional previsto na Constituição equatoriana de 2008 visa consolidar um sistema hiperpresidencialista, concentrando o poder político. Este artigo tem como objetivos: (i) refletir sobre o sistema de governo presidencialista em tempos de pandemia; (ii) mostrar que a Constituição equatoriana de 2008 supera as características essenciais do sistema de governo presidencialista; e (iii) propor medidas para prevenir a preocupante crise moral que emergiu em tempos de pandemia..

\section{PALAVRAS-CHAVE:}

Concentração de poder; pandemia; corrupção.

\section{SUMARIO}

Introducción.

1. Contexto de la realidad Ecuatoriana.

2. Sistema de gobierno presidencial.

2.1. Tipos de sistemas presidenciales.

2.2. Diseño hiperpresidencial en la Constitución ecuatoriana de 2008.

3. Relaciones institucionales para enfrentar la crisis sanitaria en Ecuador.

3.1. Rol de la Corte Constitucional: control de la actividad normativa de excepción. 3.2. Actividad legislativa en el marco de la pandemia.

4. Medidas para prevenir la corrupción.

Conclusiones.

Referencias bibliográficas

\section{INTRODUCCIÓN}

Bajo el principio de unidad e indivisibilidad del poder, el Estado se fracciona en funciones a las que, la Constitución, les atribuye competencias y facultades específicas, orientadas a alcanzar sus fines. La Constitución ecuatoriana 
incorpora, además de las funciones tradicionales: Ejecutiva, Legislativa y Judicial, a la Electoral y de Participación Ciudadana y Control Social.

Para definir el tipo de sistema de gobierno imperante en un país, interesa conocer la relación entre dos de las funciones del Estado: Ejecutivo-Legislativo. La denominación del sistema concuerda con aquella que ejerce mayor influencia social; así, cuando el peso dominante se asienta en la Presidencia de la República se llama presidencial; mientras que, cuando ese mayor peso recae en el parlamento, se denomina parlamentario.

La Constitución ecuatoriana, aprobada mediante referéndum realizado en septiembre de 2008, confiere amplias facultades y deberes al presidente de la república, en desmedro del legislativo, lo cual, hace que su diseño sea hiperpresidencial, concentrador del poder político, con riesgo de afectar valores democráticos y derechos de las personas opuestas; no obstante, si los poderes contextuales no acompañan al gobernante, se inscribe en el sistema de gobierno presidencial moderado, como se explica más adelante.

El amplio catálogo de facultades presidenciales permite adoptar medidas extraordinarias para enfrentar crisis, como la sanitaria provocada por el virus SARS-CoV-2 denominada COVID-19, en el marco del control constitucional sobre la justificación de la idoneidad, necesidad y proporcionalidad de las medidas de suspensión de derechos, a cargo de la Corte Constitucional; del control político de las actuaciones de la administración pública, a cargo de la Asamblea Nacional; y, la actuación jurisdiccional sobre actos y contratos indebidos, con lo cual se engrana el equilibrio del poder.

A más de la crisis sanitaria, la compleja situación económica del Ecuador es afectada por la paralización de la actividad productiva, comercial y financiera; así como, las actividades extractivas que generan fuertes implicaciones culturales, a lo que se suma una crisis moral en el sector público, evidenciada en contrataciones con altos sobreprecios en la ejecución de obras, y adquisición de bienes y servicios relacionados con la salud y alimentación; lo cual, hace imperativa la necesidad de planificar y ejecutar programas de concientización social sobre ética pública y compromiso ciudadano, con el objeto de superar la deteriorada economía y promover el desarrollo social en un ambiente cultural sano.

El presente trabajo contiene un análisis crítico descriptivo, con metodología deductiva. Tiene como objetivo general conceptualizar el sistema de gobierno presidencial; siendo sus objetivos específicos: (i) evidenciar el diseño hiperpresidencial en la Constitución ecuatoriana de 2008; (ii) analizar las relaciones institucionales para enfrentar la crisis sanitaria y económica provocada por el coronavirus; y, (iii) ensayar propuestas orientadas a prevenir comportamientos socialmente reprochables: la corrupción, con énfasis en el sector público.

En este contexto, si bien no es objeto de análisis en este estudio, no se puede obviar el impacto causado por la movilización de indígenas, obreros y otros sectores sociales, realizada en octubre de 2019, en especial en la ciudad de Quito, donde se puso en evidencia fáctica la creciente crisis económica y de gobernabilidad en el Ecuador.

En primer lugar, el texto describe el contexto general de la situación económica y sanitaria del Ecuador como preámbulo para definir al sistema de gobierno presidencial e identificar sus rasgos característicos, cuyo propósito persigue responder la pregunta: ¿qué es y cómo se diferencia el presidencialismo? Asimismo, se define y analiza la clasificación del sistema de gobierno presidencial: impotente, débil, moderado y fuerte.

Se discute en forma dialógica las relaciones entre Ejecutivo y Legislativo en el proceso de formación normativa de carácter económico urgente, el control constitucional 
a los decretos de estado de excepción a cargo de la Corte Constitucional ecuatoriana y una breve relación con las actividades de los gobiernos autónomos descentralizados, dentro del marco general de las políticas y orientaciones emanadas del Comité de Operaciones de Emergencia (COE) ${ }^{1}$ Nacional.

Por último, se trata de sostener la tesis según la cual, los comportamientos contrarios a los valores y principios éticos y morales son generalizados en la sociedad y no exclusivos de quienes ejercen actividades políticas o de servicio público, se proponen medidas de formación en valores y legislativas encaminadas a prevenir actos de corrupción, sin perjuicio de las actuaciones de juzgamiento de tales hechos.

\section{CONTEXTO DE LA REALIDAD ECUATORIANA}

El Ecuador tiene $283.560 \mathrm{~km} 2$ de extensión territorial y, según proyecciones del Instituto Nacional de Estadística y Censos (INEC), al año 2020 somos 17'510.643 habitantes; de los cuales: 8'665.937 son hombres y 8'844.706 mujeres, ubicados en 24 provincias; de la Costa (8'631.859), Sierra (7'847.136), Oriente (956.699), Islas Galápagos (33.042) y en zonas no delimitadas (41.907). Después de la separación de la Gran Colombia, y de suscrita el Acta de la Asamblea de Guayaquil de 1830, previa convocatoria de Juan José Flores, se reúne la Asamblea Constituyente de Riobamba y se forma el Estado del Ecuador, integrado por los departamentos de Azuay, Guayas y Quito (Avilés, 2020).

Desde su creación, el Ecuador adoptó la forma de Estado unitario y centralizado, con sistema de gobierno presidencial. La Constitución de 2008 declara que el Ecuador se gobierna de manera descentralizada, en cuya virtud define competencias exclusivas para cada nivel de gobierno: central,

1. El Comité de Operaciones de Emergencia es un órgano del Sistema Nacional para Emergencias y Desastres, encargado de planificar, promover y mantener la coordinación, y operación conjunta entre los diferentes niveles de gobierno e instituciones involucradas en la atención y respuesta a eventos de emergencia provocados por desastres naturales o antrópicos. regional $^{2}$, provincial, municipal y parroquial. Así como la participación de los gobiernos autónomos descentralizados en los ingresos permanentes y no permanentes del Estado central, con excepción de los provenientes del endeudamiento público ${ }^{3}$; además, de sus propios ingresos, destinados a cumplir sus competencias exclusivas, concurrentes y adicionales (Constitución de la República del Ecuador, 2008).

Entre las competencias exclusivas, atribuidas al Estado central, se encuentran las políticas de salud (art. 261.6), en cuya virtud, el sistema nacional de salud es responsabilidad del Gobierno central; mientras que la planificación, construcción y mantenimiento de la infraestructura física y los equipamientos de salud están atribuidos a los gobiernos municipales o metropolitanos (art. 264.7). Transcurridos más de once años de vigencia constitucional, tal competencia sigue bajo responsabilidad del gobierno central, en contra de la prescripción constitucional. Por el contrario, en diciembre de 2015 se publicaron las enmiendas que pretendieron prescribir, dicha competencia, como actuación optativa, siempre que el órgano rector autorice, enmienda declarada inconstitucional por la forma, mediante sentencia de la Corte Constitucional No. 018-18-SIN-CC, del 1 de agosto de 2018.

La pandemia provocada por la COVID-19 puso en evidencia la fragilidad del sistema de salud ecuatoriano, hasta llegar al colapso en la provincia del Guayas. Hasta el 31 de mayo de 2020, las cifras oficiales dan cuenta de 39.098 casos confirmados

2. Las provincias amazónicas intentaron formar la región amazónica, pero la incorporación de limitar la extensión territorial de las regiones, incorporada en el Código Orgánico de Organización Territorial, Autonomía y Descentralización, impidió su concreción y, hasta la fecha, no se ha creado ninguna región, como nivel de gobierno.

3. El artículo 271 de la Constitución de la República el Ecuador prescribe que la participación, de los gobiernos autónomos descentralizados, en los ingresos permanentes no sea menor al quince por ciento $\mathrm{y}$ los no permanentes al cinco por ciento; en tanto que, el Código Orgánico de Organización Territorial, Autonomía y Descentralización precisa que los ingresos permanentes correspondan al veintiuno por ciento y los no permanentes al diez por ciento correspondientes al Estado central, excepto los de endeudamiento público. 
Tabla 1. Mitigación frente a la IA aplicada a los Sistemas de Justicia

\begin{tabular}{|l|l|l|l|l|}
\hline \multicolumn{1}{|c|}{ PROVINCIA } & \multicolumn{1}{|c|}{ FEBRERO } & \multicolumn{2}{c|}{ MARZO } & \multicolumn{2}{c|}{ ABRIL } & \multicolumn{1}{c|}{ MAYO } \\
\hline El Oro & 224 & 240 & 533 & 546 \\
\hline Guayas & 1700 & 4853 & 10945 & 2350 \\
\hline Los Ríos & 286 & 257 & 624 & 426 \\
\hline Manabí & 530 & 485 & 1342 & 1017 \\
\hline Pichincha & 1143 & 1080 & 1249 & 1507 \\
\hline
\end{tabular}

Fuente: Dirección General del Registro Civil, Identificación y Cedulación de Ecuador, al 31 de mayo 2020.

de personas contagiadas; 3.358 personas fallecidas, previa verificación de contagio, y 2.154 muertes probables por COVID-19 (El Universo, 2020). Sin embargo, se puede aseverar que tanto el número de personas contagiadas, como el de fallecidas es mayor a las cifras oficiales. La afirmación sobre personas fallecidas se aprecia al comparar los registros de defunciones inscritas en el Registro Civil, durante los meses de: febrero, marzo, abril y mayo de 2020 en las provincias más afectadas, tales como: El Oro, Guayas, Los Ríos, Manabí y Pichincha.

El cuadro precedente evidencia la marcada diferencia en el número de personas inscritas en el Registro Civil de Ecuador como fallecidas, antes y durante la pandemia. Así, por ejemplo: en la provincia del Guayas, en febrero fueron registradas 1.700 personas, en tanto que, en abril 10.945 y en mayo 2.350. En Manabí se registran: en febrero 530 personas fallecidas, mientras que en abril 1.342 y en mayo 1.017. Esta información del órgano público facultado para inscribir nacimientos, matrimonios y fallecimientos, difiere en forma significativa respecto a la información oficial en cuanto al número de personas fallecidas por COVID-19 en el Ecuador.

La propagación del coronavirus evidenció la crisis del sistema sanitario público y privado ecuatoriano, aparentemente fortalecido en los últimos años. La organización del sistema, cuanto los equipos, materiales y herramientas resultaron insuficientes para prevenir y afrontar una pandemia tan agresiva como es la COVID-19. Al punto que, en abril los hospitales de la provincia del Guayas colapsaron, la recolección y depósito de cadáveres en los cementerios ocurrió con retrasos, generó angustia y desesperación entre los familiares de las personas contagiadas, el gobierno tuvo que organizar una ardua labor para recoger los cadáveres en la ciudad de Guayaquil, y garantizar así el derecho a la dignidad humana durante la muerte de las personas.

Quito, la ciudad capital del Ecuador, también presentó altos índices de personas contagiadas, en buena medida, debido a frecuentes aglomeraciones motivadas en razones laborales y, de relaciones sociales, si bien, el número de fallecidos no resulta alarmante, pero, no por ello es indiferente, la preocupación ciudadana se mantiene álgida debido a la manifiesta dificultad para controlar la propagación del virus.

Todas las provincias fueron ubicadas en un primer momento en semáforo rojo por parte del Comité de Operaciones de Emergencia (COE) Nacional; Sin embargo, la decisión de cambiar al color amarillo o verde $^{4}$ corresponde adoptar, en primer

4. El Comité de Operaciones de Emergencia adoptó el sistema de semaforización por provincias y cantones; en virtud del cual, el semáforo en rojo implica alto riesgo 
lugar, a cada COE Cantonal presidido por el alcalde del respectivo cantón y ratificada por el COE Nacional, una especie de consulta y responsabilidad compartida.

Por otra parte, la crisis económica ecuatoriana, existente desde antes de la pandemia, se acrecentó debido a la paralización de las actividades económicas y productivas dado el confinamiento obligatorio. La pérdida de empleos públicos y privados es el resultado de la drástica reducción de los ingresos tributarios y petroleros en el sector público, y de las ventas en el sector privado.

Ecuador es uno de los países latinoamericanos más afectados en su economía, debido al gasto público superior a los ingresos, el excesivo endeudamiento interno y externo; así como la eliminación y consumo de los ahorros provenientes del fondo petrolero, lo que impidió la atención satisfactoria de las necesidades originadas durante la crisis sanitaria. La abatida economía nacional se agrava por la disminución de la actividad productiva y comercial en el sector privado.

El Fondo Monetario Internacional (FMI) aprobó una línea de crédito flexible para Colombia por el valor de 10.800 millones de dólares, 11.000 millones para el Perú y 23.930 millones para Chile, mientras que para el Ecuador fue de 643 millones de dólares. La diferencia entre los valores monetarios se sustenta en el grado de confianza en el manejo de las finanzas públicas y la cantidad disponible de fondos ahorrados por cada país.

Desde el 16 de marzo hasta el 31 de mayo de 2020, el confinamiento ha ocasionado pérdidas acumuladas de USD 15.863 millones de dólares, de los cuales, una parte sufrió el sector productivo privado paralizado en un

a la salud debido a la contaminación del coronavirus, se mantienen suspendidas las actividades públicas y privadas, la movilización es restringida, entre otras medidas extremas; el color amarillo, consiste en que el riego es mediano, por tanto se autorizan ciertas actividades públicas y privadas, disminuye la restricción a la movilidad; y, el color verde, implica que el peligro está superado y retornan las actividades a la normalidad. setenta por ciento, en especial el comercio, seguido de servicios y manufactura. También, fue afectado el sector petrolero debido a la rotura de dos oleoductos y la baja del precio del barril de petróleo. La agricultura, agroindustria, exportaciones y medicinas también fueron afectadas, pero, en menor medida, esto es, en un cuatro por ciento en conjunto (El Comercio, 2020).

Además de la crisis sanitaria y económica descritas, durante la pandemia, se evidenció otra crisis: la ética dentro del servicio público en colusión con empresas privadas. Los actos de corrupción en la adquisición de insumos médicos, alimentos e infraestructura hospitalaria descubiertos por periodistas de investigación, motivaron la auditoría a cargo de la Contraloría General del Estado (CGE) e investigaciones de la Fiscalía General del Estado (FGE). Tales conductas provocan una sensación generalizada de desconfianza en las instituciones públicas, lo cual amerita prontas y pertinentes medidas legislativas y de política pública, conforme se analizará más adelante.

Frente a la escalada de actos de corrupción denunciados durante la vigencia del estado de excepción decretado el 16 de marzo de 2020, el 01 de junio de 2020 la FGE hizo pública la decisión de conformar una fuerza de tarea multidisciplinaria, con el propósito esencial de fortalecer las capacidades técnicas, investigativas y operativas de la Unidad Nacional de Transparencia y Lucha contra la Corrupción. Los resultados fueron inmediatos. Bajo la dirección de aquella fuerza de tarea, la FGE allanó domicilios, detuvo a un expresidente de la república, un prefecto provincial, un asambleísta en funciones, entre otros funcionarios públicos procesados penalmente.

En el marco de este desolador contexto nacional, se presentó esta investigación analítica sobre el diseño y coordinación institucional, las decisiones legislativas y el control de la Corte Constitucional a las actuaciones para enfrentar la crisis sanitaria, económica y social en el Ecuador, para concluir con propuestas de ensayo encaminadas a prevenir, más que a sancionar, 
actos reñidos con la moral pública: la corrupción.

\section{SISTEMA DE GOBIERNO PRESIDENCIAL}

El sistema de gobierno presidencial surge en la Constitución de los Estados Unidos de América, aprobada por los constituyentes de Filadelfia el año de $1787^{5}$, el mismo que se expandió por toda América, con matices que los diferencian. El Ecuador adoptó este sistema desde su constitución como Estado, en el año 1830 (Oyarte, 2014, 293). Por tanto, resulta pertinente analizar variables del sistema presidencial, con énfasis en el Ecuador.

La república surge y se consolida a partir de la Revolución Francesa de 1789. Se accede al poder político mediante elección popular, por períodos fijos y alternados. Por regla general el gobierno es descentralizado $y$ delimitado por el ordenamiento jurídico al que se subordinan gobernados y gobernantes, estos últimos, tienen la obligación de rendir cuentas de sus actos y son responsables por las acciones u omisiones durante su gestión.

La república es una forma de gobierno, caracterizada por la división de las funciones del Estado y su régimen político de elección, representación, participación, alternancia y responsabilidad (Borja, 2010, 97). Es la antítesis de la monarquía absoluta, del viejo régimen, en la cual el poder es hereditario y vitalicio, todas las facultades las concentra el gobernante, su voluntad es superior al ordenamiento jurídico. El gobernante toma el nombre de rey o monarca.

En el sistema presidencial, el jefe del Estado es al mismo tiempo jefe de Gobierno, elegido por el pueblo, en forma directa o indirecta, para un período predeterminado; nombra o sustituye libremente a los miembros del gabinete y dirige el Ejecutivo; por tanto, el acceso y permanencia en el ejercicio del poder político no dependen de

5. Al respecto el artículo 2 de la Constitución de los Estados Unidos de América determina que "Se deposita el poder ejecutivo en un presidente de los Estados Unidos de América". la mayoría parlamentaria (Sartori, 2003, 98). También, se define como el sistema en el cual el presidente es siempre jefe del Ejecutivo, elegido por votación popular directa o indirecta y, su período -igual que el fijado para los legisladores- es fijo (Mainwaring y Shugart, 2002). En consecuencia, tanto el presidente como los legisladores tienen origen democrático, elegidos mediante sufragio universal, directo y secreto.

La elección indirecta ocurre en los Estados Unidos de América. Consiste en que los electores, mediante sistema de representación por mayoría, eligen grandes electores en igual número que senadores $\mathrm{y}$ representantes por cada Estado, encargados de elegir al presidente y vicepresidente de la federación. Por lo general, quien obtiene mayoría de votos populares alcanza el mayor número de grandes electores, con excepción de los años 1876, 1888 y 2000, en que el Colegio Electoral superó al número de votos alcanzados por la organización política triunfante (Oyarte, 2014, 304).

En América Latina, la elección indirecta combinada con voto censitario prevaleció durante el siglo XIX. Para entonces, los encargados de designar autoridades eran quienes obtenían la condición de electores: pequeños grupos de personas adineradas e influyentes, con quienes el candidato debía consensuar para obtener el apoyo de la mayoría absoluta que para entonces imperaba. El Ecuador aplicó ese procedimiento hasta el año 1852. Los ciudadanos de cada parroquia, reunidos en asamblea parroquial, escogían electores del cantón, quienes conformaban la asamblea provincial para designar a los diputados provinciales; finalmente el Congreso Nacional elegía al presidente de la república y en algunos casos, calificaba la elección de nuevos diputados y senadores (Grijalva, 1998, 61).

En la actualidad, la mayoría de países de América, eligen presidente en forma universal, directa y secreta. Es decir los ciudadanos empadronados consignan su voto por el candidato de su preferencia, entre los propuestos por las organizaciones 
políticas competidoras, y no a través de grandes electores.

Entre los elementos característicos que distinguen al sistema de gobierno presidencial, en términos generales y adecuados a nuestra realidad, destacan los siguientes:

a) El presidente de la república es electo por el pueblo en forma directa o indirecta, para un período fijo. La legislatura no interviene en su elección o conclusión de funciones. Tanto el acceso como la permanencia en el poder no dependen de la voluntad legislativa.

b) La potestad ejecutiva es responsabilidad del presidente de la república, dotado de facultades propias de jefe de Estado y jefe de Gobierno.

c) El presidente nombra y remueve a los ministros-secretarios de Estado, cuya permanencia no requiere de la confianza del parlamento.

d) Tanto el presidente como sus ministros-secretarios de Estado no pueden ser legisladores, debido a la incompatibilidad con la facultad fiscalizadora.

e) El presidente no puede disolver la Función Legislativa, pero ésta puede censurar y destituir al jefe del Ejecutivo, en los casos previstos en la Constitución.

f) El presidente participa en el proceso de formación normativa. Tiene iniciativa legislativa, sanciona o veta las leyes; $y$, puede convocar a consulta popular.

Con fundamento en las características anotadas se puede afirmar que el principio de división de funciones, o equilibrio de poderes tiende a ser más claro en el sistema presidencial, en especial por la independencia de funciones originada en que, tanto el presidente como los legisladores, son electos por el pueblo para un período fijo y gozan de legitimidad democrática; pero, entre ellas deben existir necesarios vínculos de colaboración y cooperación para alcanzar los fines esenciales del Estado.

Tales características se oponen a las del sistema de gobierno parlamentario, en el que predomina el parlamento. La jefatura de Estado la ejerce un monarca o la persona elegida por el pueblo; mientras que la jefatura del Gobierno la cumple quien cuente con apoyo de la mayoría parlamentaria que interviene en la formación del gabinete. En cuyo caso, el acceso y permanencia del jefe de Gobierno y del gabinete dependen del apoyo de la mayoría parlamentaria. El tiempo de permanencia en el poder es indeterminado.

Las condiciones óptimas para la eficacia del gobierno en un sistema presidencial es un gobierno unido; que cuente con el apoyo de la mayoría parlamentaria, sin embargo, cuando carece de respaldo, la indisciplina en los partidos políticos facilita llegar a acuerdos para aprobar leyes, lo que se convierte en una válvula de seguridad del presidencialismo (Sartori, 1999).

El gobernante del Ecuador desde el año $2008^{6}$ hasta el 2017 contó con suficiente apoyo parlamentario para aprobar las leyes de su interés, cuya relación entre Ejecutivo y Legislativo es discutible debido a los rasgos de subordinación antes que, de coordinación, bajo la justificación del interés superior de realizar el proyecto político en marcha.

La débil relación de poder entre el Ejecutivo y el Legislativo conlleva a la búsqueda de acuerdos necesarios sobre temas de carácter legislativo. Por desgracia, no escapan acuerdos económicos indeseables, atentatorios a la ética y la moral pública, cuyos escándalos de corrupción constituyen poderosas armas contra el sistema democrático y sus instituciones. Ecuador, no está exento de esa lamentable realidad.

\subsection{Tipos de sistemas presidenciales}

Así como existen distintos tipos de sistemas de gobierno: presidencial, parlamentario, semipresidencial, el sistema presidencial tiene distintas clasificaciones

6. Si bien, el gobierno del expresidente Rafael Correa Delgado inició el 15 de enero del año 2007, al no haber postulado candidatos al Congreso Nacional no tuvo representación parlamentaria, sino a partir de la Asamblea Constituyente de Montecristi, cuando inició la tarea de redactar una nueva Constitución, el 29 de noviembre de 2007 y concluyó el 25 de octubre de 2008. 
según los autores. Karl Loewenstein diferenció entre presidencialismo puro, atenuado y parlamentarismo aproximado (Loewenstein, 1949). Por su parte, Carpizo distingue, desde una perspectiva de la realidad político-constitucional, entre presidencialismo hegemónico, equilibrado y débil (Carpizo, 2007, 194). En tanto que, según la tipología propuesta por Basabe y seguida por Salgado, el presidencialismo se integra por dos dimensiones analíticas: la primera, según la capacidad política derivada de las competencias y facultades atribuidas al presidente; y la segunda, se relaciona con los poderes contextuales (Valdivieso y Rivera, 2015, 144).

El mayor o menor poder político atribuido al presidente de la república es visto como motivador de estabilidad. En esencia, se refiere a la capacidad para ejecutar la agenda política o programa de gobierno, es lo que Shugart y Carey llaman poderes legislativos y no legislativos (Shugart y Carey, 1991). Mientras que, los poderes contextuales consisten en la legitimidad o apoyo popular y parlamentario a la gestión presidencial que le permite mayor o menor capacidad de maniobra sobre los actores críticos al régimen.

Los gobiernos con poco respaldo popular hacen concesiones, a veces contrarias a su propuesta de gobierno; se ven forzados a preocuparse no solo por cumplir sus deberes, sino de mantenerse en el poder. En tanto que, los gobiernos con amplio respaldo popular reducen las protestas, gozan de capacidad para minimizar los impactos de la opinión pública crítica y, como consecuencia, tienen mayor capacidad para aprobar leyes y ejecutar su plan de gobierno.

El conjunto de poderes políticos y contextuales, desde la perspectiva de Basabe, Valdivieso y Rivera (Valdivieso y Rivera, 2015), permite clasificar al sistema de gobierno presidencial en: presidencialismo impotente, débil, moderado y fuerte, este último denominado también hiperpresidencial.
Al presidencialismo impotente le caracterizan diseños institucionales con pocas herramientas para la gestión, además de contar con escaso respaldo legislativo y mínimo apoyo popular; el gobernante necesita negociar los contenidos legislativos y ceder espacios de poder a la oposición política o social. El escaso margen de actuación gubernamental debido a las pocas facultades y competencias previstas en la Constitución limitan la capacidad para prestar servicios públicos y sociales considerados primordiales en beneficio de los habitantes del territorio nacional.

El resultado es la inestabilidad política e incoherencia de las políticas públicas. En el gobierno impotente, los gobernantes se preocupan más por mantener el poder, que por gobernar. Así, el tipo de gobierno impotente resulta indeseable debido a la ineficacia para promover mejoras económicas y sociales, en especial de las personas más pobres, carentes de autosuficiencia para acceder a la educación, salud, vivienda, alimentación; es decir, a condiciones mínimas de vida digna.

El sistema presidencial débil ofrece diseños institucionales con suficientes herramientas de gestión gubernamental, pero con mínimo respaldo legislativo y baja aceptación popular; es decir, si bien cuenta con poderes políticos adecuados, carece de los contextuales, tiene dificultad para aplicar su plan de gobierno si no considera los problemas sociales y económicos predominantes en la coyuntura. El escaso apoyo legislativo dificulta aprobar las leyes, el deterioro del respaldo popular genera conflictos, con la consecuente inmovilidad $\mathrm{y}$ bloqueos que impiden ejercer un buen gobierno.

Antes del año 2007, el Ecuador enfrentó conflictos sociales, huelgas de trabajadores, movilizaciones indígenas $\mathrm{y}$ otras formas de protesta acompañadas de alta inestabilidad política, cuyo resultado fue que tres presidentes de la república, electos democráticamente, en forma sucesiva, no concluyan el período de gobierno. En octubre de 2019 se produjo un fuerte y violento 
levantamiento indígena, acompañado de transportistas y trabajadores, con intentos desestabilizadores que no concluyó con el derrocamiento del presidente.

En el presidencialismo moderado pueden coexistir varias combinaciones: (i) gobierno con amplio respaldo popular, con mayoría legislativa, pero pocas herramientas formales para gobernar; (ii) gobierno con amplias competencias y facultades, poco respaldo legislativo y amplio respaldo popular; y (iii) gobiernos con amplias capacidades formales para actuar, suficiente respaldo legislativo, pero impopular. Por tanto, debe sortear dificultades. Los gobiernos tienden a ceder a sectores políticos y sociales afines, sin considerar a los opuestos, si carecen de apoyo legislativo gobiernan por decreto o acuden a la consulta popular para legitimar decisiones o para aprobar leyes.

El actual presidente del Ecuador cuenta con amplias facultades determinadas en la Constitución. Al acceder al poder, el 24 de mayo de 2017, obtuvo mayoría legislativa, sin embargo, las diferencias con el gobierno que le precedió, provocaron la división del bloque oficialista. Por lo que, el gobierno, con cierta dificultad, ha concertado acuerdos políticos y textos legislativos con bancadas independientes y de otras fuerzas políticas para aprobar las leyes de su iniciativa y evitar enjuiciamientos políticos.

Con referencia al apoyo popular, según la encuestadora Cedatos-Gallup, al iniciar el cuarto y último año de gobierno, el nivel de aprobación del presidente equivale al 18.7\% y su credibilidad al 14.7\% (El Universo, 2020); mientras que, la encuestadora Click Report, en febrero de 2020, aseguró que el $7.99 \%$ de la población calificó de buena gestión y el $7.72 \%$ cree en la palabra del presidente (Expreso, 2020), el apoyo popular es escaso.

El alto endeudamiento interno y externo heredado y acentuado, la escasa inversión privada nacional y extrajera, así como los bajos precios del barril de petróleo, entre otras causas influyentes en los escasos ingresos del Presupuesto General del Estado, tienen incidencia directa en el bajo nivel de aprobación y credibilidad del presidente de la república y su gobierno.

Por lo expuesto, se puede afirmar que el gobierno ecuatoriano mantiene: a) amplias competencias y facultades constitucionales; b) carece de mayoría legislativa del partido gobernante, pero, aún con dificultad, sus propuestas legislativas son aprobadas; $y$, c) las encuestas evidencian poco respaldo popular; en cuya virtud necesita hacer concesiones; tal es el caso de la eliminación de la tabla de contribuciones de los servidores públicos y aportes de las empresas privadas para que pase el proyecto de Ley de Apoyo Humanitario, calificado de económico urgente, tramitado durante la crisis sanitaria. Esta realidad permite afirmar que se trata de un gobierno moderado.

En tanto que, en el gobierno fuerte, denominado hiperpresidencial, coexisten tres condiciones favorables: a) amplio catálogo de competencias y facultades formales para actuar; b) mayoría legislativa favorable al gobierno; y, c) vasto respaldo popular, que le permite materializar el plan de gobierno sin mayor dificultad, los bloqueos políticos o sociales se reducen a su mínima expresión. Basta acordar al interior del partido o partidos gobernantes para aprobar y ejecutar las leyes y las políticas públicas.

Estos gobiernos, frecuentemente se niegan a escuchar las voces de sectores políticos o sociales disímiles, se dan casos de persecución o limitación de las opiniones críticas al gobierno; y, los sectores políticos, sociales, económicos o de cualquier naturaleza, nacionales o extranjeros, contradictorios son blanco de ataques o exclusiones, con el riesgo frecuente de caer en la intolerancia política, hasta llegar a desgastar el apoyo popular (Valdivieso y Rivera, 2015, 145).

La concentración de poderes jurídicos y fácticos en el primer mandatario de una nación, en menoscabo de la función Legislativa, Judicial y de los gobiernos locales, por lo que, resulta necesario agregar 
un conjunto de instituciones políticas relacionadas, directa o indirectamente, con la intervención del Ejecutivo producen, como efecto característico, un sistema político hiperpresidencial (Nino, 2013, 570).

El gobierno del Ecuador, desde el 2008 hasta el 2017 contó con amplios poderes políticos y contextuales descritos en líneas anteriores, por lo que, claramente se inscribe en el tipo de gobierno fuerte o hiperpresidencial.

\subsection{DISEÑO HIPERPRESIDENCIAL EN LA CONSTITUCIÓN ECUATORIANA DE 2008}

La Constitución de la República del Ecuador 2008 mantiene la tradición ecuatoriana y americana al prever un sistema de gobierno presidencial. Se inscribe en sus características esenciales al prescribir que "La Presidenta o Presidente de la República ejerce la Función Ejecutiva, es el Jefe del Estado y de Gobierno y responsable de la administración pública"7.

Las atribuciones y deberes constitucionales (art. 147 y 418) fijados para el presidente de la república, relativas a la definición de la política exterior, suscripción y ratificación de instrumentos internacionales; el ejercicio de la máxima autoridad de las Fuerzas Armadas; velar por la soberanía e independencia del Estado; y, dirigir la defensa nacional, son inherentes a la condición de jefe de Estado.

Además, tiene facultad para definir y dirigir las políticas públicas de la Función Ejecutiva; proponer el Plan Nacional de Desarrollo para su aprobación; dirigir la administración pública en forma desconcentrada; crear, modificar o suprimir ministerios y entidades públicas; nombrar y remover a los ministros-secretarios de Estado y otros funcionarios; $y$, velar por

7. Así prevé el artículo 141 de la Constitución de la República el Ecuador, elaborada por la Asamblea Nacional Constituyente y que, sometida a referéndum, obtuvo el respaldo del $63.93 \%$ de los votantes. Se encuentra publicada en Quito: Registro Oficial Nro. 449, del 20 de octubre de 2008. el orden y seguridad son inherentes a la condición de jefe de Gobierno.

De la misma forma, los artículos: 135, 138, 139, 140, 147 y 148 de la Constitución le confieren competencias en materia legislativa: a) iniciativa legislativa general y exclusiva para crear, modificar o suprimir impuestos, aumentar el gasto público o modificar la división político-administrativa del país; b) sancionar o vetar los proyectos de ley aprobados por la Asamblea Nacional; c) declarar la urgencia de ciertos proyectos en materia económica; d) ejercer potestad reglamentaria derivada y autónoma; e) convocar a períodos extraordinarios de sesión de la Asamblea Nacional para que trate asuntos específicos; $y$, f) expedir decretos-leyes de urgencia económica, previo control de constitucionalidad, cuando haya resuelto disolver la Asamblea Nacional.

Conforme a los artículos: 147.14, 441, 442 y 444, ibidem, el presidente puede convocar a consulta popular sobre temas de interés nacional que estime conveniente o para enmendar la Constitución, mediante referéndum directo o ratificatorio de un proyecto de reforma parcial o para integrar una asamblea constituyente que tenga como finalidad proponer un nuevo texto constitucional.

Según los artículos 208.10 y 434 de la Constitución, también interviene indirectamente en la designación del procurador general del Estado y superintendentes, mediante ternas definidas con criterio de especialidad y mérito, seleccionados por el Consejo de Participación Ciudadana y Control Social. Las Superintendencias son órganos de vigilancia, supervisión y control, creados por la ley. Además, presenta candidatos para integrar la Corte Constitucional.

Como resultado de haber destituido -al margen de la Constitución- a tres presidentes elegidos democráticamente, en menos de una década, los artículos 130 y 148 de la Constitución, buscan equilibrar el poder mediante la muerte cruzada. Es decir, si la Asamblea Nacional puede destituir al 
presidente, el jefe de Estado puede disolver la Asamblea Nacional, cuyas causales son: arrogación de funciones, grave crisis política y conmoción interna, para la disolución legislativa se añade la obstrucción reiterada e injustificada de la ejecución del Plan Nacional de Desarrollo por parte de la Función Legislativa.

El artículo 147.18 de la Constitución le atribuye, en materia judicial: indultar, rebajar o conmutar penas privativas de libertad. El indulto incide en la remisión o perdón de la pena, la rebaja implica disminuir el tiempo de privación de la libertad resuelta por el juez; la conmutación consiste en modificar o cambiar la sanción impuesta. En cualquier caso, afecta o modifica la decisión judicial. El presidente debe ofrecer razones justificativas excepcionales, aunque la Constitución no determine limitaciones.

Una vez descritas, en términos generales, las competencias y facultades que la Constitución ecuatoriana de 2008 atribuye al presidente de la república, y al compararlas con las aprobadas en 1979 y 1998, según la tabla de puntuaciones definida por Valdivieso y Rivera, que por razones de espacio no se desarrollan en este aporte, se concluye que las aprobadas en 1979 y 1998 corresponden al tipo de presidencialismo moderado; en tanto que, las del 2008 al presidencialismo fuerte o hiperpresidencial.

\section{RELACIONES INSTITUCIONALES PARA ENFRENTAR LA CRISIS SANITARIA EN ECUADOR}

Conforme a los artículos 3.1, 32 y 261.6 de la Constitución y los artículos 6 y 9 de la Ley Orgánica de Salud, corresponde al Estado central, por intermedio del Ministerio de Salud Pública, ejercer la competencia para definir la política nacional y prestar los servicios de promoción y atención integral de salud, observando los principios de equidad, universalidad, solidaridad, interculturalidad, calidad, eficacia, eficiencia, precaución y bioética, con enfoque de género y generacional, por tanto, al Estado le corresponde garantizar, sin discriminación alguna, el derecho a la salud.
El primer caso verificado de coronavirus en el Ecuador, fue diagnosticado el 28 de febrero de 2020 e informado a la ciudadanía mediante cadena nacional, al día siguiente. La primera paciente fue una mujer adulta mayor ecuatoriana, quién llegó a la ciudad de Guayaquil, proveniente de España, el 14 de febrero del mismo año. El 11 de marzo de 2020, la Organización Mundial de la Salud (OMS), por intermedio de su director general declaró al brote del coronavirus como pandemia global y solicitó a los países intensificar las medidas preventivas para mitigar su propagación, proteger a las personas, trabajadores de la salud y para salvar vidas humanas.

La ministra de Salud Pública, mediante Acuerdo Ministerial No. 00126-2020, de 11 de marzo de 2020, declaró el estado de emergencia sanitaria en todos los establecimientos del Sistema Nacional de Salud, para prevenir un posible contagio masivo en la población. Ordenó que la Red Pública de Salud priorice los recursos económicos, de talento humano y adopte las medidas necesarias para afrontar la emergencia. Las circunstancias obligaron a adoptar medidas preventivas para evitar la propagación de contagios, proteger la salud y la vida de las personas contagiadas por el coronavirus, tales como la cuarentena obligatoria o aislamiento social (Acuerdo Ministerial, 2020).

En cuanto a la potestad para declarar el estado de emergencia sanitaria, existe una aparente contradicción entre el numeral 11 del artículo 6 de la Ley Orgánica de Salud, que faculta al Ministerio de Salud para solicitar la declaratoria de tal estado, sin determinar qué autoridad tiene facultad para tal efecto, con la disposición prevista en el artículo 57 de la Ley Orgánica del Sistema Nacional de Contratación Pública que faculta al ministro de Estado para "emitir resolución motivada que declare la emergencia".

El propósito de declarar la situación de emergencia radica en contratar de manera directa, rápida, inclusive con empresas extranjeras sin exigir el requisito de domiciliación y bajo la responsabilidad de 
la máxima autoridad, las obras, los bienes y servicios estrictamente necesarios para superar la causa que la origina, en este caso, la crisis sanitaria, amenazante de los derechos a la salud y la vida, para lo cual, las instituciones del Estado pueden modificar el presupuesto para fijar los recursos económicos, materiales y talento humano necesario.

Conforme al artículo 24 del Reglamento a la Ley de Seguridad Pública y del Estado, el 13 de marzo de 2020, se activó el (COE), que opera bajo el principio de descentralización subsidiaria previsto en el artículo 390 de la Constitución; esto es, que la gestión de riesgos implica la responsabilidad directa de las instituciones dentro de su ámbito geográfico (Reglamento 2010).

Los gobiernos municipales, en uso de la facultad legislativa atribuida en el artículo 240 de la Constitución, expidieron ordenanzas para obligar a usar mascarillas, mantener una distancia de dos metros entre sí, regular la circulación vehicular urbana, acceder a mercados y centros de abasto, suspender actividades no esenciales, entre otras. La inobservancia conlleva a sanciones pecuniarias, clausura de negocios y a otras acciones, para asegurar la eficacia normativa.

Conforme consta en el contexto de este artículo, el COE Nacional definió cambiar la orden de aislamiento total hacia el distanciamiento social con base en un mecanismo de semaforización: rojo, amarillo y verde, cuya decisión de fijar el color, con sus efectos predeterminados, corresponda a los COE cantonales presididos por el alcalde, tal capacidad decisoria se sustenta en el conocimiento cercano de la realidad viviente de cada localidad, además de contar con información técnica proporcionada por las autoridades, en el ámbito de sus competencias, decisión que debe ser refrendada por el COE Nacional para efectos de la necesaria coordinación interinstitucional e intersectorial.

\subsection{ROL DE LA CORTE CONSTITUCIONAL: CONTROL DE}

\section{LA ACTIVIDAD NORMATIVA DE EXCEPCIÓN}

El presidente, en uso de la facultad conferida en el artículo 164 constitucional, el 16 de marzo de 2020 expidió el Decreto Ejecutivo No. 1017, en el cual declaró el estado de excepción por calamidad pública en el territorio nacional, dados los casos de coronavirus confirmados y la declaratoria de la pandemia por parte de la Organización Mundial de la Salud (OMS), que advierten alto riesgo de contagios que causarían efectos adversos a los derechos a la vida, salud y convivencia pacífica, por un período de sesenta días.

Dicho Decreto dispone: a) la movilización institucional para coordinar esfuerzos en el marco de sus competencias; b) la suspensión del ejercicio del derecho a la libertad de tránsito, así como al de asociación y reunión, cuyas restricciones deban ser reguladas por el COE Nacional para prevenir la generación de contagios en el desarrollo de actividades habituales; c) declara el toque de queda en los términos que disponga el $\mathrm{COE}$ Nacional; d) restringe la libertad de tránsito y movilidad a nivel nacional, con excepción de los sectores que contribuyan a mitigar los efectos de la pandemia: proveer de alimentos, medicamentos, combustibles y la prestación de servicios públicos; e) suspende la jornada presencial de trabajo y de estudios en todos los niveles; entre otras órdenes.

El estado de excepción, al que se conoce con la denominación: estado de emergencia, estado de sitio, facultades extraordinarias con las diferencias que caracterizan en cada caso "es la institución creada para enfrentar lo que Jean Rivero denomina "hipótesis de peligro público" y que autoriza a concentrar poderes en una autoridad, limitar ciertos derechos o, en general, adoptar medidas que no se admiten en circunstancias normales" (Aguilar, 2010, 61).

Por su parte, la Corte Constitucional ecuatoriana, sostiene que "El estado de excepción... implica un mecanismo o medio que contempla el propio Estado constitucional para afrontar una circunstancia extraordinaria que desborda 
la normalidad, superando a las alternativas de implementación y a los mecanismos de intervención que el ordenamiento jurídico prevé de manera ordinaria" (Dictamen No. 1-20-EE/20, par. 7).

La limitación de derechos no es total sino relativa. Así, la disposición de quedarse en casa no equivale a privar la libertad, sino que existen excepciones: a) para adquirir alimentos o medicinas puede salir una persona por familia; b) para cumplir actividades laborales relacionadas con sectores estratégicos, prestación de servicios públicos esenciales y otras similares, las personas pueden movilizarse dentro de horarios restringidos. La prohibición de mantener reuniones fue desatendida, al punto que el 25 de mayo los trabajadores y estudiantes realizaron manifestaciones públicas, contra las medidas legislativas y económicas, en varias ciudades del país.

Precisa destacar que las condiciones económicas de las familias de escasos recursos económicos impiden mantener el confinamiento por un tiempo prolongado. Dada la carencia de medios necesarios $\mathrm{y}$ suficientes para atender elementales necesidades para su subsistencia, en especial las personas dedicadas al trabajo informal o de subempleo, se vieron compelidas a salir a la calle, siendo esa su única opción.

El 17 de marzo de 2020 ingresa a la Corte Constitucional, el Decreto Ejecutivo No. 1017 para el control de constitucionalidad conforme a los artículos 166 y 436.8 de la Constitución, a fin de evitar actuaciones desmedidas que afecten derechos. La Corte, mediante dictamen No. 1-20-EE/20, de 19 de marzo de 2020, justificó la idoneidad, necesidad y proporcionalidad de las medidas adoptadas, emitió dictamen favorable de constitucionalidad y dispuso que el Estado dicte medidas para proteger a los ciudadanos en condición de riesgo y observe las limitaciones pertinentes para evitar excesos.

Mediante Decreto Ejecutivo No. 1052, de 15 de mayo de 2020, se renueva el estado de excepción por treinta días adicionales; y, la Corte Constitucional, mediante Dictamen No.
2-20-EE/20, de 22 de mayo de 2020, emitió dictamen favorable de constitucionalidad, con exhortos y disposiciones jurisdiccionales para garantizar los derechos a: la salud, educación y conectividad, al trabajo, de los pueblos indígenas, de personas en situación de movilidad humana, de personas privadas de libertad, de protección por violencia contra mujeres; además, resalta la necesidad de observar la transparencia en los procesos de contratación pública y advierte la responsabilidad de los servidores públicos por acciones u omisiones dolosas, en las que incurran durante la vigencia del estado de excepción.

\subsection{ACTIVIDAD LEGISLATIVA EN EL MARCO DE LA PANDEMIA}

El presidente presentó dos proyectos de ley calificados de económico-urgentes, denominados: Ley de Apoyo Humanitario y Ley de Ordenamiento de las Finanzas Públicas. La primera tiene por fin dotar, a la administración pública, de los instrumentos normativos para combatir la crisis sanitaria; $y$, la segunda, ofrecer herramientas jurídicas para regular los ingresos públicos, el gasto, los préstamos gubernamentales y las tarifas de bienes y servicios.

Precisa destacar que, conforme al artículo 135 del texto constitucional, el presidente tiene iniciativa legislativa privativa cuando se trate de crear, modificar o suprimir impuestos, o para aumentar el gasto público. Además, el artículo 140 ibidem le autoriza enviar, a la Asamblea Nacional, proyectos de ley calificados de urgencia en materia económica a ser aprobados, modificados o negados en el plazo máximo de treinta días contados desde su recepción. La calificación de urgencia puede hacerse a un proyecto mientras se discute en la Asamblea Nacional, excepto en casos de estado de excepción. Si la Asamblea Nacional no lo aprueba, ni niega el proyecto, en el referido plazo, corresponde promulgar como decreto-ley y publicar en el Registro Oficial.

La Asamblea Nacional aprobó, con dificultades y la cantidad mínima de votos favorables, los dos proyectos de ley referidos que, se espera, permitan mejorar 
las condiciones económicas y sanitarias del país. Cabe destacar que tanto las comisiones legislativas, cuanto el pleno de la Asamblea Nacional, sesionan de manera regular vía telemática, para cumplir los plazos fijados en la Constitución y para tratar otros temas de su agenda, tal como resolvió el Consejo Administrativo de la Legislatura mediante Reglamento para la implementación de las sesiones virtuales y el teletrabajo emergente en la Asamblea Nacional.

La gravedad de la crisis económica obliga al Gobierno central a reducir el tamaño del Estado mediante fusión o eliminación de instituciones y empresas públicas, no renovar contratos de servicios ocasionales, terminar nombramientos provisionales y suprimir puestos en el sector público. Asimismo, la paralización de la actividad productiva y baja del precio del petróleo reduce los ingresos permanentes y no permanentes del Presupuesto General del Estado, por lo que reducirán asignaciones a los gobiernos autónomos descentralizados y otras entidades.

Reducir el gasto público no será suficiente para equilibrar las finanzas públicas; por tanto, el Estado requiere acudir a más endeudamiento con organismos multilaterales de crédito y gobiernos amigos; así se anunció que, en uso de la facultad constitucional, dispondrá el pago anticipado del impuesto a la renta por parte de personas con ingresos mensuales superiores a cinco mil dólares y las empresas privadas no afectadas durante la pandemia, a fin de obtener ingresos para cubrir parte del déficit presupuestario; $y$, mediante Decretos Ejecutivos 1041 y 1947 dispuso el aporte equivalente al cincuenta por ciento de la remuneración mensual del presidente (USD 5.072 a 2.536), vicepresidente de la república (USD 4.869 a 2.434), ministros (USD 4.436 a 2.231) y viceministros hasta el 24 de mayo de 2021, fecha en la que termina el período de su mandato.

El Ecuador enfrenta una constante afectación a los recursos económicos del Estado. Si bien los procesos de contratación de obras o adquisición de bienes cumplen las formalidades previstas en la Ley Orgánica del Sistema Nacional de Contratación Pública y su reglamentación, existen frecuentes denuncias por irregularidades en el valor contratado, mala calidad de los productos o no recepción de lo contratado y pagado con fondos públicos.

El Tribunal Penal de la Corte Nacional de Justicia del Ecuador, en el caso denominado "sobornos 2012-2016", el 7 de abril de 2020 dictó sentencia condenatoria a ocho años de prisión e indemnización por el valor de USD 14'745.297,00, no ejecutoriada, contra un expresidente, un exvicepresidente, varios exministros-exsecretarios de Estado, exfuncionarios de alto nivel gubernamental y contratistas privados. Por otros casos, relacionados con actos de corrupción en PETROECUADOR EP, se encuentran privados de libertad el mismo exvicepresidente, un exministro, exgerentes de PETROECUADOR EP y más exfuncionarios públicos.

Durante la crisis generada por la pandemia, varios hospitales del Instituto Ecuatoriano de Seguridad Social (IESS) se encuentran intervenidos y la Fiscalía General del Estado (FGE) investiga posibles adquisiciones irregulares de medicinas e insumos médicos. Hospitales del Ministerio de Salud se encuentran bajo investigación por presuntos actos de corrupción denunciados en procesos de contratación de obras (Hospital básico de Pedernales), compra de fundas o bolsas plásticas para personas fallecidas e insumos médicos. La Secretaría Nacional de Gestión de Riesgos (SNGR) también enfrenta una investigación por sobreprecios en la adquisición de alimentos destinados a personas de escasos recursos económicos.

Dependencias municipales de Quito, Guamote, Milagro y otros, así como de las prefecturas de Guayas y Pichincha, además de domicilios de funcionarios y exfuncionarios, incluido otro expresidente, también fueron allanados o se encuentran en etapa de investigación por parte de la FGE, debido a denuncias públicas por presuntos sobreprecios en la adquisición de pruebas para detectar contagios del coronavirus, 
mascarillas y otros insumos destinadas a la protección ciudadana frente a la pandemia.

Según un estudio de Transparencia Internacional, difundido en enero de 2020, el Índice de Percepción de la Corrupción (IPC), en Ecuador fue de 32 y se ubica en el puesto 11 de los 18 países latinoamericanos y 93 de los 180 analizados (El Telégrafo, 2020). Por tanto, la percepción sobre la corrupción en Ecuador es preocupante.

Los hechos relacionados con actos de corrupción, cometidos antes y durante la pandemia, causan la impresión de que se trata de un mal generalizado y forma parte del sistema político y de gestión pública; en el modelo de Estado constitucional, la promoción y protección de derechos es prioridad del Estado La corrupción, además de constituir delitos, afecta a la democracia y violenta derechos humanos, dado que, incide en la mala calidad de gestión, incrementa costos de bienes y servicios y el riesgo de impedir que los ciudadanos accedan a servicios sociales como la atención médica, con calidad y calidez.

Por lo expuesto, es indispensable adoptar medidas para prevenir actuaciones indebidas en las instituciones del Estado y en el sector privado que interviene en procesos de contratación pública. A continuación, se esbozan propuestas encaminadas a mitigar el cáncer social de la corrupción que pueden ser aplicadas en Ecuador y otros países con similares comportamientos humanos.

\section{MEDIDAS PARA PREVENIR LA CORRUPCIÓN}

$\mathrm{Si}$ aceptamos que, tanto los administradores públicos cuanto los electos por el pueblo, para ejercer cargos o dignidades de representación política son parte de una sociedad con altos índices de inseguridad en relación a sus bienes, así como prácticas cotidianas como saltarse la fila, copiar en exámenes u obtener beneficios indebidos, además de actividades relacionadas con el narcotráfico, debemos admitir que la corrupción es un fenómeno social; por tanto, no basta la amenaza de sanciones por duras que sean, sino que para mitigarla es necesario adoptar medidas preventivas. Es un problema de conciencia colectiva.

En forma de ensayo, se proponen medidas encaminadas a prevenir actos inmorales que afectan a los recursos económicos y materiales, así como a los servidores públicos, en especial los encargados de procesos de selección de proveedores del Estado; y, de los servidores públicos en general, con especial énfasis en las personas relacionadas con el manejo de las relaciones de poder, la economía y la gestión del Estado. Eso, sin perjuicio de sanciones efectivas cuando incurran en delitos contra el Estado y las personas.

\section{a) Formación ética y conciencia ciudadana}

El artículo 3 de la Constitución prescribe que el Estado tiene el deber primordial de garantizar la ética laica como sustento del quehacer público, así como a vivir en una sociedad democrática, libre de corrupción. Además, el artículo 234 ibidem obliga al Estado a garantizar la formación y capacitación continua de los servidores públicos, mandato constitucional que merece la acción prioritaria de las autoridades de todos los niveles de gobierno y de las funciones e instituciones públicas y privadas, estatales y no estatales.

Para cumplir este deber, las instituciones públicas y privadas de educación primaria, media y superior, entidades de derecho público y empresas privadas, organizaciones políticas, colegios profesionales y organizaciones sociales en general deben planificar y ejecutar programas regulares de formación ética y conciencia ciudadana respecto a la importancia de observar comportamientos moralmente aceptables para la convivencia ciudadana, el orden, la paz y el desarrollo económico y social, libre de corrupción.

El Ministerio de Educación y el Consejo de Educación Superior diseñarán programas de formación ética y conciencia ciudadana sobre la importancia de la rentabilidad de la ética y la práctica permanente de valores, para ser 
ejecutados en cada ciclo de estudios. Tales programas deben ser ejecutados anualmente en todas las funciones e instituciones del Estado, públicas y privadas; sin perjuicio de lo cual, se realicen campañas masivas a través de medios de comunicación colectiva.

\section{b) Control posterior en los contratos públicos}

La Ley Orgánica del Sistema Nacional de Contratación Pública prevé varios tipos de procedimientos contractuales, según la cuantía. El procedimiento a cargo de cada entidad contratante puede ser objeto de control posterior de la Contraloría General del Estado (CGE) mediante examen de auditoría interna o externa, lo cual, no es suficiente. De manera general, las irregularidades son identificadas por periodistas de investigación y difundidas por redes sociales, antes que por las instituciones responsables del control.

Las instituciones del Estado, independientemente del tipo y monto de contratación, deben remitir el expediente completo, dentro de los quince días posteriores a la suscripción del contrato, a la CGE para que un área técnica especializada verifique la legalidad del procedimiento, analice los precios unitarios, comparando tanto con los fijados en contratos similares y los costos del mercado; y, en caso de encontrarse irregularidades remita la documentación respectiva a la Fiscalía General del Estado (FGE) para su inmediata investigación.

La Fiscalía, al contar con suficientes elementos probatorios, hará públicos los hechos y la identificación de las personas presuntamente responsables, lo cual se espera tenga como resultado que, de una parte, se abstengan de manipular los precios $y$, de otra, identificar irregularidades con prontitud para ser sometidos a investigación de la FGE, como órgano del poder público autónomo, y al escrutinio público.

La mayoría de personas, y más las expuestas al escrutinio público, tienen legítima preocupación por mantener incólume su imagen, honor y dignidad personal como familiar, lo cual debe ser protegido, con tal propósito la Fiscalía tiene el deber de hacer públicos los hechos, al contar con pruebas suficientes para acreditar, en juicio, la responsabilidad penal de los involucrados. Al mismo tiempo, los ciudadanos accederán al derecho constitucional de ser debidamente informados sobre las actuaciones de sus gobernantes.

\section{c) Selección de servidores de carrera y ocasionales \\ Las unidades de talento humano de} cada entidad son responsables de planificar el talento humano, es decir, determinar la necesidad de incorporar o prescindir de personal, suficiente para alcanzar los fines y objetivos institucionales; además, seleccionan nuevos servidores públicos previo concurso de méritos y oposición para cargos permanentes o sin aquel concurso en casos de servicios ocasionales o profesionales, y los de libre nombramiento y remoción o de confianza que lo hace la autoridad administrativa institucional.

Si bien el artículo 228 de la Constitución ecuatoriana dispone que el ingreso al servicio público, el ascenso y la promoción se realicen mediante concursos de méritos y oposición, con excepciones, la burocracia en el Ecuador es poco profesional, a menudo carente de independencia e imparcialidad, tiende o es forzada a manifestar su apoyo político para acceder o permanecer en un cargo público $y$, no es extraño que sean obligados a actuar en forma indebida. Una autoridad carente de valores y principios éticos y morales puede sentir el derecho a maltratar o acosar a sus subalternos para alcanzar propósitos indeseables. Lo contrario, una autoridad ética y profesional respeta y apoya a sus subalternos, facilita las actividades laborales para obtener resultados óptimos.

El acceso al servicio público basado en el clientelismo: favores, amistad o presiones de cualquier naturaleza, afecta a la profesionalidad, imparcialidad, eficacia y transparencia en el ejercicio de la función pública. Urge encontrar salidas a esta larga crisis nada novedosa. 
Para superar las dificultades existentes, se propone que las unidades de talento humano se limiten a planificar el talento humano. La selección por concurso de méritosy oposición para cargos permanentes, ocasionales o profesionales, con excepción del de libre nombramiento y remoción, debe estar a cargo de un instituto técnico especializado, independiente y autónomo de todas las funciones e instituciones del Estado, es más, se debe prohibir expresamente la injerencia directa o indirecta de las autoridades requirentes. A su vez, los servidores públicos así seleccionados deben gozar de estabilidad plena, para tal efecto, la legislación debe impedir la cesación arbitraria de funciones mediante mecanismos como la compra de renuncia obligatoria con indemnización o la terminación anticipada de contratos ocasionales.

$\mathrm{Al}$ alejar la facultad de intervenir, por si o por interpuesta persona, a las autoridades de elección popular o de libre designación, en la selección de personal administrativo, técnico, de servicios u obreros, el resultado esperado es menos populismo político y clientelismo electoral, menor número de personas enroladas en instituciones públicas; mayor eficiencia, eficacia y efectividad, así como la recuperación de la confianza ciudadana en las instituciones públicas.

Las personas seleccionadas por méritos propios sentirán que no deben favor alguno, sabrán que la única forma de ingresar al sector público es mediante la formación académica y desarrollo de capacidades para triunfar en un concurso por sus méritos, valores y capacidades; y, en consecuencia, responderán al interés general de la sociedad.

Es decir, se espera promover una burocracia profesional, técnica, imparcial y comprometida con el interés público e institucional, como mecanismo eficaz para prevenir actos de corrupción. Los cambios no serán inmediatos, pero, no será posible alcanzarlos si se empieza en un determinado momento.

\section{CONCLUSIONES}

La crisis económica del Ecuador, agravada por la crisis sanitaria por el coronavirus, influye en el decrecimiento económico en el año 2020, entre el 7.3 y 9.6\% del Producto Interno Bruto (PIB), según estimaciones anunciadas por el Banco Central del Ecuador. Para mitigar los impactos, el gobierno tiene la responsabilidad de adoptar medidas económicas estructurales, previamente concertadas con actores económicos, sociales y políticos.

La pandemia evidenció que el sistema integral de salud del Ecuador es deficitario en su capacidad de respuesta apropiada y oportuna para prevenir y sanar enfermedades complejas como el coronavirus, por lo que, amerita revisar políticas, la estructura, los equipamientos, el talento humano, los procesos de adquisición y en general, todos los aspectos relacionados con la prevención y protección del derecho a la salud humana, física y mental.

La amplitud de atribuciones que el ordenamiento jurídico ecuatoriano confiere a la Función Ejecutiva permite al gobierno adoptar medidas emergentes y coordinar acciones en respuesta a la diversidad de situaciones excepcionales que se presentan, bajo el control jurisdiccional de la Corte Constitucional y político de la Asamblea Nacional, para evitar excesivas restricciones a los derechos constitucionales y proteger a grupos humanos expuestos a riesgos de mayor intensidad. El control de las medidas debe ser permanente, a fin de evitar excesos y verificar la temporalidad, razonabilidad, proporcionalidad y adecuación a los estándares internacionales de derechos humanos.

El diseño institucional ecuatoriano es claramente hiperpresidencial que pone en riesgo del equilibrio de poderes, de anular contrapesos, de afectar los principios democráticos, libertades y la transparencia en la gestión pública. Sin embargo, si los poderes contextuales no son favorables al gobernante, se inscribe en el sistema de gobierno presidencial moderado cuyo efecto 
político es el de limitar posibles excesos en el ejercicio del poder público.

Cualquiera sea el tipo de sistema de gobierno presidencial, la escasa práctica social de valores éticos y morales conlleva a que autoridades y funcionarios con poder político influyan en procesos de contratación pública e incorporación de servidores públicos para aprovechar, en forma indebida, de los fondos públicos u obtener prebendas en su beneficio o de terceros. Por tanto, es urgente adoptar medidas estructurales para que la sociedad viva valores éticos y morales y así, lograr que la administración pública sea profesional, técnica, imparcial, eficiente y confiable, mediante procesos de selección por méritos, absolutamente alejados de todo tipo de influencias perniciosas.

Ninguna medida política o jurídica será suficiente para mejorar la economía y los comportamientos sociales sin una sociedad comprometida culturalmente con los valores democráticos, éticos y morales deseables para alcanzar el éxito por mérito propio, sin afectar a terceras personas, públicas o privadas.

\section{REFERENCIAS BIBLIOGRÁFICAS}

» Aguilar, J. P. (2010). Entre la retórica de lo nuevo y la persistencia del pasado: La Corte Constitucional y los Estados de excepción. Iuris dictio, 10 (13), 59-89.

» Avilés, E. (s.f.) Historia del Ecuador. En Enciclopedia del Ecuador. Disponible en https://n9.cl/5s96. Consultado el 20 de mayo de 2020.

» Borja, R. (2010). Sociedad, cultura y derecho. (3ra Ed). Quito: Planeta.

»Carpizo, J. (2007). Concepto de democracia y sistema de gobierno en América Latina. Bogotá: Universidad Externado de Colombia.

» Grijalva, A. (1998). Elecciones y representación política. Quito: Corporación Editora Nacional.

» Loewenstein, K. (1949). The Presidency outside the United States: A study in comparative political institutions. Journal of Politics, 11 (3), 22-27.

» Mainwaring, S. y Shugart, M. (2002). Presidencialismo y democracia en América Latina. Buenos Aires: Paidós.

» Nino, C. S. (2013). Fundamentos del derecho constitucional. Análisis filosófico, jurídico y politológico de la práctica constitucional (Cuarta reimpresión). Buenos Aires: Astrea.

» Oyarte, R. (2014). Derecho constitucional ecuatoriano y comparado. Quito: Corporación de Estudios y Publicaciones.

» Sartori, G. (1999). La ingeniería constitucional y sus límites. Teoría y realidad constitucional. (3), 79-87. Disponible en: https://n9.cl/bux8o. Recuperado el 25 de mayo de 2020.

» Sartori, G. (2003). Ingeniería contitucional comparada (Tercera ed.). México: Fondo de Cultura Económica.

» Shugart, M. y Carey, J. (1991). Presidents and assemblies, constitutional design and electoral dynamics. Cambridge: Cambridge University Press.

» Valdivieso, P. y Rivera, L. (2015). Presidencialismo fuerte en Ecuador (1979/1998/2008). En: Derecho constitucional e instituciones políticas. Derechos 
humanos y justicia constitucional: ensayos en honor del prof. Hernán Salgado Pesantes. Quito: Corporación de Estudios y Publicaciones.

\section{Legislación}

» Acuerdo Ministerial 00126-2020. Registro Oficial No. 160, Quito, 12 de marzo de 2020.

» Asamblea Nacional del Ecuador. (19 de marzo de 2020). Reglamento para la implementación de las sesiones virtuales y el teletrabajo emergente en la Asamblea Nacional expedido por el Consejo Administrativo. Recuperado de https://n9.cl/h7xdo.

» Constitución de la República del Ecuador. Registro Oficial No. 449, Quito, 20 de octubre de 2008.

» Decreto Ejecutivo No. 1017. Registro Oficial Suplemento No. 163, Quito, 20 de marzo de 2020.

» Decreto Ejecutivo No. 1052. Registro Oficial Suplemento No. 209, Quito, 22 de mayo de 2020.

» Ley Especial de Descentralización y Participación Social. Registro Oficial No. 169, Quito, 8 de octubre de 1997.

» Ley Especial de Distribución del 15\% del Presupuesto del Gobierno Central para los Gobiernos Seccionales. Registro Oficial No. 27, Quito, 20 de marzo de 1997.

» Reglamento a la Ley de Seguridad Pública y del Estado. Registro Oficial Suplemento No. 486, Quito, 30 de septiembre de 2010.

\section{Casos judiciales}

» Corte Constitucional del Ecuador. Dictamen No. 1-20-EE-20, de 19 de marzo de 2020.

$»$ Corte Constitucional del Ecuador. Dictamen No. 2-20-EE-20, de 22 de mayo de 2020.

\section{Documentos}

» Casos de Coronavirus en Ecuador: 39098 confirmados, 3358 fallecidos. (31 de mayo de 2020). El Universo. Recuperado el 6 de junio de 2020 de https://n9.cl/ qibx0

» Instituto Nacional de Estadística y Censos. (2020). Proyecciones de la población ecuatoriana, por años calendario. Período 2010-2020. Recuperado el 1 de octubre de 2020 de https://www.ecuadorencifras.gob.ec/proyecciones-poblacionales/.

» Lenín Moreno inicia último año presidencial con 14\% de credibilidad. (24 de mayo de 2020). El Universo. Recuperado el 05 de junio de 2020 de: https:// n9.cl/5a0d5.

» Montenegro, J. (6 de febrero de 2020). Encuestadora: la popularidad de Lenín Moreno toca fondo. Expreso. Recuperado el 20 de mayo de 2020 de: https://n9.cl/ gvfl.

» Orozco, M. (31 de mayo de 2020). USD 15863 millones suman pérdidas causadas por pandemia en Ecuador. El Comercio. Recuperado el 06 de junio de 2020 de: https://n9.cl/59mr.

» Quezada, A. (14 de mayo de 2020). Corrupción en tiempos del Covid-19. El Telégrafo. Recuperado el 15 de junio de 2020 de: https://n9.cl/icwu. 